\section{Growth of Potato Plantlets In Vitro Is Different When Provided Concurrent Versus Alternating Blue and Red Light Photoperiods}

\author{
Ruey-Chi Jao ${ }^{1}$ \\ Department of Information Management, Chien Kuo Institute of Technology, \\ No. 1, Jieshou N. Rd., Changhua City, Taiwan, 500, R.O.C. \\ Wei Fang ${ }^{2}$ \\ Department of Bio-Industrial Mechatronics Engineering, National Taiwan \\ University, No. 1, Sec. 4, Roosevelt Rd., Taipei, Taiwan, 106, R.O.C. \\ Additional index words. light-emitting diodes, light quality, potato plantlets, blue light, red light
}

Abstract. Effects of concurrent vs. alternating blue and red light using light-emitting diodes (LEDs) on the photomixotrophic growth of potato plantlets in vitro were investigated. All seven treatments had the same $5.53 \mathrm{~mol} \cdot \mathrm{m}^{-2}$ daily light integral (DLI), photoperiod (16-hour day/8-hour night) and similar proportion of red light $(45 \%)$ and blue light $(55 \%)$. Results showed that the fresh/dry weight accumulation of potato plantlets in vitro under the concurrent blue and red light was superior than that under the alternating blue and red light, indicating that the simultaneous coexistence of blue and red light are necessary for optimum plantlet growth. Low PPF with long duration was better than high PPF with short duration under same DLI. Within the concurrent blue and red light treatments, when the duration of blue light was shorter than that of red light, timing of the blue light affected the growth of potato plantlets in vitro. Providing blue and red light together at the beginning of the photoperiod resulted in optimal growth, however plantlets illuminated with alternately blue and red light had significantly less fresh/dry weight accumulation.

Tubular fluorescent lamps (TFLs) are the most popular artificial light source in micropropagation. However, their use constitutes the highest nonlabor costs $(65 \%$ of the total electricity fee) in a tissue culture lab (Dooley, 1991; Standaert de Metsenaer, 1991). Leading researchers and commercial tissue culturists look for alternative light sources and more efficient ways of illuminating cultures. Light-emitting diodes (LEDs) are a potential alternative to TFLs due to their low forward current, small, wavelength specific, solid state construction, low degradation and long life (Bula et al., 1991; Brown et al., 1995; Fang and Jao, 2000).

Plant growth and development is affected by light intensity, light quality, duration and photoperiod (Taiz and Zeiger, 1991). When under light saturation point in vitro, plantlet growth and photosynthetic rate increase as light increases. Growth, morphology and differentiation of in vitro plantlets are also affected by light quality (Econmou and Read, 1987). Red light was shown significantly enhance stem elongation of Pelargonium plantlets in vitro while blue light inhibited shoot length (Appelgren, 1991). TFLs used as main light source and red and far-red light using LEDs as supplemental promoted the growth

Received for publication 22 Oct. 2002. Accepted for publication 7 May 2003.

${ }^{1}$ Assistant Professor.

${ }^{2}$ Professor. To whom reprint requests should be addressed. E-mail: weifang@ntu.edu.tw of potato plantlets in vitro even though the relative proportion of supplementary light was very small (Iwanami et al., 1992). However, Miyashita et al. (1994) used red LEDs as main light source and TFLs as supplemental found that the morphology rather than the growth (dry weight and leaf area) of plantlets was affected under same PPF. Light intensity and quality had influences on the morphology and growth of potato plantlets (Solanum tuberosum L. cv. Benimaru) in vitro. Hayashi et al. (1993) found that the dry weights per plantlet were greater in the shorter lighting cycle treatments than in the longer lighting cycle treatments. Hoenecke et al. (1992) found that red LEDs inadequate to grow lettuce (Lactuca sativa 'Grand Rapids') unless blue light was added. when using sunlight or TFLs. LEDs are a wavelength specific light source and with a ing blue and red light environments can be provided. Continuous light, pulse light, or both, can be generated using an LED light source with a specially designed driver (Jao and Fang, 2003).

The focus of this study was the comparison of blue and red light provided at the same time vs. provided separately with the light integral remaining the same during each light period. Such studies can be conducted using LEDs. This study investigated the effects of concurrent vs. alternating blue and red light under same DLI, same portion of blue and red light and same photoperiod on the photomixotro-
Blue and red wavelengths always coexist proper driver design, concurrent or alternat-

\section{Materials and Methods}

Plant materials and culture conditions. Single node cuttings (fresh weight $=11.8$ $\pm 1.8 \mathrm{mg}$ and dry weight $=1.3 \pm 0.4 \mathrm{mg}$ ) of potato plantlets (Solanum tuberosum L. cv. Kennebec), with leaf attached were established from 28-d-old plantlets and subcultured to $10 \times 10 \mathrm{~cm}, 785-\mathrm{mL}$ cylindrical poly vinyl chloride (PVC) containers (Yu-Ping Corp., Taiwan) containing $50 \mathrm{~mL}$ of MS (Murashige and Skoog, 1962) medium with $20 \mathrm{~g} \cdot \mathrm{L}^{-1}$ sucrose and $8 \mathrm{~g} \cdot \mathrm{L}^{-1}$ agar. The medium $\mathrm{pH}$ was adjusted to 5.8 before autoclaving at $110 \mathrm{kPa}$ for $20 \mathrm{~min}$ at $120^{\circ} \mathrm{C}$. Each vessel contained 5 explants. Vessels were incubated in a controlled environment at $25 \pm 2{ }^{\circ} \mathrm{C}$ and $50 \pm$ $10 \%$ relative humidity $(\mathrm{RH})$.

Light treatments. All cultures were illuminated using blue and red LEDs programmed to provide a $16 \mathrm{~h}$ day $/ 8 \mathrm{~h}$ night photoperiod and DLI was $5.53 \mathrm{~mol} \cdot \mathrm{m}^{-2}$ (measured using LI-1800, LI-COR, Lincoln, Nebr.). The percentage of daily blue and red light integral vs. DLI was 55\% and 45\%, respectively. The LED lighting system used was described previously by Jao and Fang $(2003,2004)$.

Seven illumination patterns were examined (Table 1). Treatment 1 consisted of equal units of blue and red LEDs with all units providing continuous illumination during the light period. In treatments 2 through 4 , continuous illumination from red LEDs was provided during the light period; however, illumination from blue LEDs was provided at a greater intensity (ratio of 2 blue LEDs to 1 red LEDs) and shorter duration ( $8 \mathrm{~h}$ ). The three treatments differed in regards to the time frame in which blue LEDs were illuminated. In treatment 2 , blue LEDs were lit during the first $8 \mathrm{~h}(8 \mathrm{~h} \mathrm{on} / 8 \mathrm{~h}$ off $)$ of the $16 \mathrm{~h}$-photoperiod, whereas in treatments 3 and 4 , blue LEDs were illuminated during the middle $8 \mathrm{~h}(4 \mathrm{~h}$ off/ $8 \mathrm{~h}$ on/ $4 \mathrm{~h}$ off) and latter $8 \mathrm{~h}$ ( $8 \mathrm{~h}$ off/ 8 $\mathrm{h}$ on), respectively. Alternating periods using 2 units of either red or blue light were used to provide the $16 \mathrm{~h}$-photoperiod. In treatment 5 , blue LEDs alone were illuminated during the first $8 \mathrm{~h}$ and red LEDs alone used to illuminate cultures, whereas in treatment 6 , the LED illumination pattern was reversed. Treatment 7 differed from 5 and 6 in that illumination was provided by only red LEDs during the first and final $4 \mathrm{~h}$ of the light period and illumination provided solely by blue LEDs during the middle $8 \mathrm{~h}$. The LEDs were located on top of the cultural vessel at $1 \mathrm{~cm}$ apart.

Treatments were arranged in a completely randomized design with subsampling consisting of five individual samples/treatment (35 samples total). Each treatment was conducted three times.

Experimental design and statistical analysis. Fresh/dry weight of shoots and roots were measured for each treatment of all samples $28 \mathrm{~d}$ after planting. Data were analyzed using Duncan's multiple range test and orthogonal contrasts using SAS (SAS Inst., Cary, N.C.). 


\section{Results and Discussion}

Growth of potato plantlets was greatest when illuminated continuously for $16 \mathrm{~h}$ with concurrent blue and red LEDs (Table 2). Contrast 1 also showed this result (Table 3). Dry weight of plantlets was significantly less than treatment 1 when plantlets were illuminated with shorter, more intense intervals of blue light (treatments 2 and 4). In addition, growth of plantlets was most inhibited when illuminated with alternating patterns of blue and red LEDs (treatments 5, 6, and 7) or when providing blue light only during the middle $8 \mathrm{~h}$ of the 16-h light period (treatment 3 ). Treatments 2 and 4 had fewer changes in light intensity and quality throughout the light period compared with treatment 3 . Thus, plantlets growth in the former treatments exceeded plantlets incubated in the latter treatment (Table 2).

Contrast 2 showed the most significant difference indicating that $16 \mathrm{~h}$ of concurrent blue and red light (treatment 1 ) is superior than double intense but alternating blue and red light (treatments 5, 6, and 7). Contrast 3 showed that dry weight of plantlets was significantly different when plantlets were illuminated with $8 \mathrm{~h}$ of concurrent (treatments 2, 3, and 4) and alternating (treatments 5, 6, and 7) blue and red light (Table 3).

No matter how blue light was provided, continuous red-16 h treatments (treatments 1 to 4 ) were better than providing half duration, double intense red light treatments (Contrasts 4). Contrast 1 also revealed that no matter how red light was provided, continuous blue-16 h treatment (treatment 1) was better than providing half duration, double intense blue light treatments.

No significant difference was found between treatments 2 and 4 (Table 2). It meant that providing blue light at the beginning or end of photoperiod with the same light intensity and durations could get the same growth condition. But both treatments 2 and 4 are better than treatment 3 , which provided the blue light at the middle of photoperiod, causing more fluctuations in light intensity and light quality.

If provided with alternating blue and red light (Treatments 5, 6, and 7), the sequence of blue and red light and the partitioning of the duration of blue light had no effects on fresh/dry weight accumulation under the same DLI, same portion of blue and red light and same photoperiod (Contrast 5, Table 3).

Contrasts 1 to 3 also indicated that the longer the concurrent period for blue and red light, the better the fresh/dry weight accumulation under the same DLI, same portion of blue and red light and same photoperiod conditions. The differences might be attributed to the light intensity and light quality fluctuations during the light period. With a temporal stress formed when light intensity and light quality changed suddenly.

Emerson, et al. (1957) found that the photosynthetic rate of Chlorella was increased two to three times when provided with red $(650-680 \mathrm{~nm})$ and far red $(700-720 \mathrm{~nm})$ light simultaneously. The observation was termed
Table 1. Descriptions of seven treatments in supplying blue light and red light.

\begin{tabular}{|c|c|c|c|c|c|c|c|}
\hline \multirow{3}{*}{$\frac{\text { Treatments }}{1}$} & \multirow{2}{*}{$\begin{array}{c}\begin{array}{c}\text { LED } \\
\text { color }\end{array} \\
\mathrm{B}\end{array}$} & \multicolumn{4}{|c|}{$\begin{array}{l}\text { Light period } \\
(16 \mathrm{~h})^{\mathrm{z}}\end{array}$} & \multirow{3}{*}{$\begin{array}{c}\text { PPF } \times \text { Duration }^{y} \\
53 \times 16=848 \\
43 \times 16=688\end{array}$} & \multirow{3}{*}{$\begin{array}{c}\% \text { of total }^{\mathrm{x}} \\
55 \\
45\end{array}$} \\
\hline & & - & - & - & - & & \\
\hline & $\mathrm{R}$ & - & - & - & - & & \\
\hline \multirow[t]{3}{*}{2} & B & - & - & - & - & $106 \times 8=848$ & 55 \\
\hline & - & & & & & - & - \\
\hline & $\mathrm{R}$ & - & - & - & - & $43 \times 16=688$ & 45 \\
\hline \multirow[t]{3}{*}{3} & B & - & - & - & - & $106 \times 8=848$ & 55 \\
\hline & - & & & & & - & - \\
\hline & $\mathrm{R}$ & - & - & - & - & $43 \times 16=688$ & 45 \\
\hline \multirow[t]{3}{*}{4} & B & - & - & - & - & $106 \times 8=848$ & 55 \\
\hline & - & & & & & - & \\
\hline & $\mathrm{R}$ & - & - & - & - & $43 \times 16=688$ & 45 \\
\hline \multirow[t]{3}{*}{5} & B & - & - & - & - & $106 \times 8=848$ & 55 \\
\hline & - & & & & & - & - \\
\hline & $\mathrm{R}$ & - & - & - & - & $86 \times 8=688$ & 45 \\
\hline- & - & - & & & & - & - \\
\hline \multirow[t]{3}{*}{6} & B & & & - & - & $106 \times 8=848$ & 55 \\
\hline & --- & & & & & - & - \\
\hline & $\mathrm{R}$ & - & - & - & - & $86 \times 8=688$ & 45 \\
\hline- & - & - & - & - & - & - & - \\
\hline \multirow[t]{3}{*}{7} & B & - & - & - & & $106 \times 8=848$ & 55 \\
\hline & - & & & & & - & - \\
\hline & $\mathrm{R}$ & - & - & - & - & $86 \times 4+86 \times 4=688$ & 45 \\
\hline \multirow[t]{2}{*}{-} & - & - & - & - & - & - & - \\
\hline & & $--4 \mathrm{~h}--$ & ---- & ---- & $--4 \mathrm{~h}--$ & & \\
\hline
\end{tabular}

${ }^{2} 16-\mathrm{h}$ light/8-h dark photoperiod.

${ }^{y} \mathrm{PPF}$ is in $\mu \mathrm{mol} \cdot \mathrm{m}^{-2} \cdot \mathrm{s}^{-1}$ and duration is in hours. One unit of blue and red light equals 53 and $43 \mu \mathrm{mol} \cdot \mathrm{m}^{-2} \cdot \mathrm{s}^{-1}$, respectively.

× $(\mathrm{PPF} \times$ Duration of $\mathrm{B}$ or $\mathrm{R}) /(\mathrm{PPF} \times$ Duration of $\mathrm{B}+\mathrm{PPF} \times$ Duration of $\mathrm{R})$.

Table 2. Fresh and dry weight of potato plantlets grown for $28 \mathrm{~d}$. For description of treatments, see Table 1 and text.

\begin{tabular}{lccclllll}
\hline & \multicolumn{3}{c}{ Fresh wt $(\mathrm{mg})$} & & \multicolumn{3}{c}{ Dry wt $(\mathrm{mg})$} \\
\cline { 2 - 4 } \cline { 7 - 9 } Treatment & Shoot & Root & \multicolumn{1}{c}{ Total } & & Shoot & Root & Total \\
\hline 1 & $900.5 \mathrm{a}^{\mathrm{z}}$ & $199.8 \mathrm{a}$ & $1100.3 \mathrm{a}$ & & $61.8 \mathrm{a}$ & $11.1 \mathrm{a}$ & $72.9 \mathrm{a}$ \\
2 & $848.1 \mathrm{~b}$ & $195.6 \mathrm{a}$ & $1043.7 \mathrm{~b}$ & & $53.0 \mathrm{~b}$ & $10.2 \mathrm{~b}$ & $63.2 \mathrm{~b}$ \\
3 & $504.8 \mathrm{~d}$ & $179.8 \mathrm{~b}$ & $684.6 \mathrm{~d}$ & & $31.5 \mathrm{e}$ & $9.8 \mathrm{~b}$ & $41.3 \mathrm{c}$ \\
4 & $681.5 \mathrm{c}$ & $187.9 \mathrm{~b}$ & $869.4 \mathrm{c}$ & & $49.4 \mathrm{c}$ & $10.8 \mathrm{a}$ & $60.2 \mathrm{~b}$ \\
5 & $497.6 \mathrm{~d}$ & $164.3 \mathrm{c}$ & $661.9 \mathrm{e}$ & & $33.4 \mathrm{~d}$ & $7.5 \mathrm{c}$ & $40.9 \mathrm{c}$ \\
6 & $491.8 \mathrm{~d}$ & $167.4 \mathrm{c}$ & $659.2 \mathrm{e}$ & & $32.1 \mathrm{~d}$ & $7.3 \mathrm{c}$ & $39.4 \mathrm{c}$ \\
7 & $491.6 \mathrm{~d}$ & $163.2 \mathrm{c}$ & $654.8 \mathrm{e}$ & & $32.0 \mathrm{~d}$ & $7.8 \mathrm{c}$ & $39.8 \mathrm{c}$ \\
\hline
\end{tabular}

${ }^{2}$ Values within a column followed by the same letters are not significantly different at the 5\% level of Duncan's multiple range tests.

Table 3. Analysis of variance summary for the total dry weight of potato plantlets. Data were analyzed using procedures for a completely randomized design with treatment comparisons made using orthogonal contrasts.

\begin{tabular}{|c|c|c|c|c|}
\hline Source & DF & Sums of squares & Mean square & F-value \\
\hline Treatment & 6 & 11665.082 & 1944.180 & $54.00^{* *}$ \\
\hline Error & 63 & 2268.223 & 36.003 & --- \\
\hline Corrected total & 69 & 13933.306 & --- & --- \\
\hline \multicolumn{5}{|l|}{ Contrasts } \\
\hline $1^{2}$ & 1 & 5524.704 & 5524.704 & $153.45^{* *}$ \\
\hline $2^{y}$ & 1 & 8074.098 & 8074.098 & $224.26^{* *}$ \\
\hline $3^{x}$ & 1 & 3305.878 & 3305.878 & $91.82^{* *}$ \\
\hline $4^{\mathrm{w}}$ & 1 & 4947.702 & 4947.702 & $137.42^{* *}$ \\
\hline $5^{\mathrm{v}}$ & 1 & 0.324 & 0.324 & $0.01^{\mathrm{Ns}}$ \\
\hline
\end{tabular}

${ }^{2}$ Treatment 1 vs. $2,3,4,5,6$, and 7 : Continuous blue and red $16 \mathrm{~h}$ vs. all other treatments.

yTreatments 1 vs. 5, 6, and 7: Concurrent blue and red for $16 \mathrm{~h}$ vs. alternating blue and red.

${ }^{x}$ Treatments 2, 3, and 4 vs. 5, 6, and 7: Concurrent blue and red for $8 \mathrm{~h}$ vs. alternating blue and red.

wTreatments 1, 2, 3, and 4 vs. 5, and 6: Continuous red $16 \mathrm{~h}$ vs. double intense red $8 \mathrm{~h}$.

Treatments 5 and 6 vs. 7: Continuous red 8 h vs. staggered red $4+4 \mathrm{~h}$.

Ns, *Nonsignificant or significant contrast at the 0.01 level, respectively. 
'Emerson enhancement effect', which laid the foundation of the discovery of the photosystems I and II of plants. Our observation on concurrent vs. alternating red (400-500 $\mathrm{nm})$ and blue (600-700 nm) light had similar enhancement effect on the growth of potato plantlets in vitro. However, the reason for such enhancement might be due to the fact that blue light increases stomatal conductance (Zeiger, 1983); thus, increasing $\mathrm{CO}_{2}$ concentration and photosynthetic efficiency inside plant cells. Another reason might be due to the fact that the absorption spectrum of chlorophyll a and b have two peaks at 400-500 nm (blue) and 600-700 $\mathrm{nm}$ (red). Although the chlorophyll can absorb only one photon at a time, light absorption can be maximized by utilizing all when blue and red LEDs are used simultaneously.

A molecule of chlorophyll that has absorbed a photon, termed 'excited state' molecule, is not stable and is ready for the photosynthetic electron transport. The time required for such chemical reactions will be different for specific wavelengths of photons carrying different amounts of energy. The lifetime of the 'excited' molecule is in the pico and nanosecond range and unless the excitation energy of the 'excited' molecule can be transferred to an appropriate 'acceptor', the chance for a chemical reaction is lost. The result of our study showed that the energy efficiency of the photosynthesis of potato plantlets with two absorption peaks of 'excited' chlorophyll was better than that with only one absorption peak 'excited' throughout the light period.

\section{Literature Cited}

Appelgren, M. 1991. Effects of light quality on stem elongation of Pelargonium in vitro. Scientia Hort. 45:345-351.

Brown, C.S., A.C. Schuerger, and J.C. Sager. 1995. Growth and photomorphogenesis of pepper plants under red light-emitting diodes with supplemental blue or far-red lighting. J. Amer. Soc. Hort. Sci. 120:808-813.

Bula, R.J., R.C. Morrow, T.W. Tibbitts, D.J. Barta, R.W. Ignatus, and T.S. Martin. 1991. Lightemitting diodes as a radiation source for plants. HortScience. 26:203-205.

Dooley, J.H. 1991. Influence of lighting spectra on plant tissue culture. Intl. Symp. of the ASAE (Amer. Soc. Agr. Eng.). Chicago.

Economou, A.S. and P.E. Read. 1987. Light treatments to improve efficiency of in vitro propagation system. HortScience. 22:751-754.

Emerson, R., R. Chalmers, and C. Cederstrand. 1957. Some factors influencing the long wavelength limit of photosynthesis. Proceedings of the National Academy of Sci. 43:133-143.

Fang, W. and R.C. Jao. 2000. A review on artificial lighting of tissue cultures and transplants. p. 108-113 In: C. Kubota and C. Chun (eds.), Transplant production in the 21st Century. Kluwer Academic. Netherlands.

Hayashi, M., T. Kozai, M. Tateno, K. Fujiwara, and Y. Kitaya. 1993. Effects of the lighting cycle on the growth and morphology of potato plantlets in vitro under photomixotrophic culture conditions. Environ. Control Biol. 31(3):169-175.
Hoenecke, M.E., R.J. Bula, and T.W. Tibbitts. 1992. Importance of 'Blue' photon levels for lettuce seedlings grown under red-light-emitting diodes. HortScience. 27: 427-430.

Iwanami, Y., T. Kozai, Y. Kitaya and S. Kino. 1992. Effects of supplemental red and far-red lighting using light emitting diode on stem elongation and growth of potato plantlets in vitro. p. 183. Intl. Symp. Transplant Production Sytems. 21-26 July 1992. Yokohama Japan. (abstr.)

Jao, R.C. and W. Fang. 2003. An adjustable light source for photo-phyto related research and young plant production. Appl. Eng. Agr. 19(5):601-608.

Jao, R.C. and W. Fang. 2004. Effects of frequency and duty ratio on the growth of potato plantlets in vitro using light-emitting diodes. HortScience 39:375-379.

Miyashita, Y., T. Kimura, Y. Kitaya, and T. Kozai. 1994. Effects of \%red on the growth and morphology of potato plantlets in vitro: An experimental use of light emitting diodes (LEDs) as a light source for tissue culture. p. 47. In Abstr. Third Intl. Symp. Artificial Lighting in Hort. 23-27 Jan., 1994. Noordwijkerhout, The Netherlands.

Murashige, T. and F. Skoog. 1962. Arevised medium for rapid growth and bioassays with tobacco tissue cultures. Physiol. Plant. 15:473-497.

Standaert de Metsenaere, R.E.A. 1991. Economic considerations. p. 131-140 In: Debergh PC \& Zimmerman RH (eds.). Micropropagation. Kluwer Academic, Dordrecht, The Netherlands.

Taiz, L. and E. Zeiger. 1991. Plant Physiology. 1st ed., 179-264. Benjamin/Cummings Publishing Co. New York.

Zeiger, E. 1983. The biology of stomatal guard cells. Ann. Rev. Plant Physiol. 34:441-475. 